\title{
Psychological distress, drug use, and internet use: the association with poor sleep quality in a sample of secondary school students
}

Anthony A. Olashore ( $\square$ olawaleanthonya@gmail.com )

University of Botswana https://orcid.org/0000-0002-7608-0671

Oluyemi O. Akanni

Federal neuropsychiatric Hospital Uselu, Benin City

Olaniyi O. Ayilara

Federal Neuropsychiatric Hospital, Uselu, Benin City

\section{Primary research}

Keywords: Anxiety, Depression, Tobacco, Internet use, Sleep quality, Adolescents

Posted Date: May 12th, 2020

DOI: https://doi.org/10.21203/rs.3.rs-27378/v1

License: (1) This work is licensed under a Creative Commons Attribution 4.0 International License.

Read Full License

Version of Record: A version of this preprint was published on September 11th, 2020. See the published version at https://doi.org/10.1177/1178221820957306. 


\section{Abstract}

\section{Background}

Sleep problems are common among children and adolescents. Sleep quality plays a significant role in adolescents' mental health. The study aimed to determine the prevalence of poor sleep quality (PSQ) among secondary school students, identify sociodemographic factors associated with PSQ in this group, and to examine the independent associations of psychological distress, stimulant use and internet use with PSQ.

\section{Methods}

Data were collected from 420 secondary school students from four different schools who were selected using a mixture of convenience and random sampling. A set of questionnaires was administered to collect data, and it consisted of 5 sections measuring: the sociodemographic, drug use, psychological distress, internet use, and sleep quality

\section{Results}

A total of 378 questionnaires were analyzed. The prevalence of those with PSQ was $12.2 \%$. A logistic regression model showed that anxiety (AOR=1.20,95\% Cl:1.10-1.32), depression (AOR=1.12, 95\%Cl:1.001.25), and internet use (AOR=1.02, 95\% Cl:1.00-1.03) were significantly associated with PSQ.

\section{Conclusions}

PSQ commonly exists among students and has a relationship with their psychological state and potentially addictive behavior, such as internet use. A bi-directional evaluation of PSQ as a cause and, or effect of psychological and addictive problems, was further recommended.

\section{Background}

The National Sleep Foundation described good sleep quality as total sleep time of $85 \%$ or more, commencing sleep not later than half an hour while attempting sleep, waking up not more than once during the night and being able to recommence sleep within 15 minutes of an initial awakening across all age groups [1]. While sleep quantity (number of hours of sleep during the night) is an essential determinant of how "good sleep" could be defined, the quality of sleep is a more important determinant of optimal sleep as the range of sleep quantity vary widely from one individual to the other [2].

Sleep problems are common among children and adolescents in Nigeria [3, 4] and beyond [5-7], and they are associated with physical and mental health indices. For example, while poor quality of sleep is associated with obesity, impaired blood lipids in adolescents [8], reduced learning capacity, and academic performance [9]; it is also associated with psychological symptoms such as depression, anxiety disorders, and behavioral disorders in studies among adolescents [9-11]. 
Another association of importance is that of sleep problems and drug use. Drug use has varying effects on sleep depending on the type, amount, and stage of use, the association between sleep quality and stimulating drugs has been established, though it remains complex [12]. Stimulants such as methylphenidate have been shown to improve both quantity and quality of sleep in a population of individuals with attention deficit hyperactivity disorder, but this claim does not appear to hold among those without the disorder $[13,14]$. Another survey involving 166 participants revealed that dependence on stimulants such as caffeine and nicotine was associated with poor quality of sleep and increased psychological distress [15].

Sleep problems have also been associated with internet use, another potentially addictive behavior, among adolescents and young adults $[7,16]$. In a study that examined the relationship between internet use and sleep-related problems in 1212 adolescents, using the Young Internet Addiction Scale, it was observed that the adolescents who had higher scores reported more problematic sleep habits and sleep problems [17].

The relationship of sleep quality with these domains of interest: psychological distress, stimulant use, and internet use have not been adequately studied, even though there are some reports on the prevalence of poor sleep quality (PSQ) among children and adolescents in Nigeria $[3,4,18]$. Undoubtedly, there is growing evidence that the rate of drug (stimulant) use is increasing among adolescents in Nigeria [19] who use stimulants to stay alert and fend off sleep [20]. Similarly, the number of internet users and abusers among adolescents in Nigeria has continued to rise [21], and the figure of adolescents suffering

from psychological problems has equally increased [22]. In a locale where data is grossly insufficient, it is apt to fill in gaps in information by conducting studies of this nature, which may be useful for other researchers, clinicians, and policymakers. With the increasing concern about students' mental health in recent years, it is, therefore, necessary to update the prevalence of PSQ among secondary school students, identify sociodemographic factors associated with it in this group, and to examine the independent associations of psychological distress, stimulant use and internet use with PSQ.

\section{Methods}

\section{Study Location and population}

This cross-sectional study was carried out in Benin City, which is the capital city of Edo State, located in the South-South geopolitical zone of Nigeria. The city is the residence of diverse ethnic groups, and it has a population of more than a million persons. Within the city are schools either owned by the government (public) or by individuals (private). The privately-owned schools obtain approval from the government to operate, and they far outnumber the public schools. The school system is such that the secondary school education is divided into junior and senior, and each is a three-year program. The study population consisted of students from both levels of secondary schools.

\section{Procedure}


Ere the collection of data, approval was obtained from the research and ethics department, Edo State Ministry of Education, and the authorities of the schools involved. Written informed consent was obtained from the participants and their parents/teachers if below the age of 18 years. Only the students who could give consent or assent and understand the English language enough to fill the questionnaire were selected.

A total of 420 questionnaires were distributed even though a sample size of 195 was calculated using a Nigerian study in which $15.5 \%$ of children and adolescents had sleep problems [18]. Sampling was based on convenience; four gender-mixed schools were picked from the numerous schools in the city. The selection was purposefully made to include two schools each from the public (government-owned) and privately owned schools. Students were thereafter randomly selected from both the junior and senior secondary levels from the chosen schools.

Two research assistants who were adequately trained were employed for the collection of data. The training entailed understanding the content of the questionnaire enough to be able to assist the students when necessary. The administration of the questionnaire was done in the classroom, mostly during the break period. Data were collected between January 22 and February 2, 2018.

\section{Measures}

A set of questionnaires which consisted of 5 sections was used for collecting data.

\section{Socio-demography}

The first section, which is the sociodemographic characteristics, was used to collect information such as the gender, age, family structure, school type, religion, ethnicity, parental figure, and academic performance of the students. It was purposefully designed and structured to meet the objectives of the study.

\section{Sleep Quality}

The Sleep Quality Questionnaire (SQQ) [23] was used to assess sleep quality in the participants. It is a 9item scale that is scored on a 5 -point scale from 0 to 4 and added together. Possible scores range from 0 to 27; the lower the score, the more severe the sleep problem, while high scores indicate sleep to be in good shape. A score of 18 and below is highly suggestive of problems with sleep using SQQ, and this was adopted as the cut off in this study (Huffington, 2016). The scale has a strong correlation $(r=0.925)$ with another sleep scale, the Sleep Condition Indicator, which has been validated and found to have good psychometric properties [23]. The reliability score of the SQQ in the current study was 0.71 .

\section{Internet Addiction}

The Internet Addiction Test [24] is a 20-item scale that assesses the general pattern of internet use and its impact on the respondent's life at work, school, home, and social. Responses are made on a 6-point Likert 
measure (0-5); thus, the possible score ranges between 0 and 100. A score of 50 and above indicates a potential internet addiction which was chosen in this study [25]. It has been widely used among students, and the scale recorded a Cronbach alpha of 0.93 in the current study.

\section{Psychological distress}

The Hospital Anxiety Depression Scale (HADS)[26] was used to screen for the presence of anxiety and depression in the participants. HADS can be used in clinical and non-clinical populations, and it consists of seven depression and anxiety items. It has been validated for use in Nigeria [27]. A higher score on each scale indicates increased psychological distress. A cut-off point of eight and above on either of the two components is regarded as a probable case diagnosis.

\section{Drug Use}

The World Health Organisation Questionnaire for Student Drug Use Surveys was developed from different parts of the world, including Nigeria [28]. For this research, only the tobacco and caffeine sections of the instrument were used to obtain information on the commonly used stimulants. Respondents are required to indicate whether they have used them in the past thirty days (current use) and the frequency of use within this period. The instrument has been used in different cultures and countries, including Nigeria.

\section{Data analyses}

Data collected were analyzed using the Statistical Package for Social Sciences (SPSS), version 22. Univariate analysis, such as frequencies, was determined in percentages and displayed in tables. Some variables, such as religion, current stimulant use, were dichotomized to enable a sufficient number of participants for analysis. Cut off points were utilized to determine the prevalence of cases of depression, anxiety, problematic internet use, and PSQ. However, the continuous scores of some of these variables were employed in further bi-variates and multi-variates analyses.

The Chi-square tests were used to determine the association between sleep quality and categorical variables such as gender, family structure, school type, academic performance, current use of stimulants (caffeine and cigarette). The sleep quality scores were tested for normality using the one-sample Kolmogorov-Smirnov tests and were found to be non-normally distributed. Hence, the non-parametric Mann-Whitney $U$ test was applied to examine the differences in the rank mean scores of age, depression, anxiety, and internet use between the normal and poor group of sleep quality. Variables such as current tobacco use, internet use, depression, and anxiety, which were significant on bi-variates analyses were included in the logistic regression model. A p-value of less than 0.05 was accepted as the level of statistical significance

\section{Results}

\section{Sociodemographic characteristics}


A total of 378 (90\%) out of the 420 questionnaires distributed were analyzed. The remaining questionnaires were discarded because of inconsistent responses or unfilled data. The participants comprised of $174(46.2 \%)$ male and 203 (53.8\%) female students. Age ranged between 10 and 21 years with a mean and median of 14.78 and 15.00 years, respectively. The sample included 189 students from the public schools, while $183(49.2 \%)$ were from private. Other characteristics of the participants are summarized in Table 1.

\section{Prevalence of PSQ and associated variables}

The prevalence of those with PSQ was $12.2 \%$, and those with problematic internet use measured $23.3 \%$. Current uses of caffeine and tobacco were $39.4 \%$ and $6.1 \%$, respectively. One hundred and twelve (29.6\%) and $48.4 \%$ of the participants scored respectively above the cut-off point for the Hospital Anxiety and Depression Scale to merit cases of depression and anxiety.

A significant association was found between PSQ and current tobacco use $(p=0.01)$. (Table 2).

Furthermore, participants with PSQ had significantly higher scores on anxiety scale $(p=0.00)$, depression scale $(p=0.00)$, and internet use $(p=0.01)$ when compared with those without sleep problems (Table 3$)$.

A binary logistic regression of the current use of tobacco, internet use, depression, and anxiety was carried out on PSQ. The result showed that anxiety, depression, and internet use were significantly associated with PSQ (Table 4).

\section{Discussion}

We investigated the prevalence of PSQ and its interaction with some identified risk factors, which include sociodemographic and clinical correlates. Our findings revealed that $12.2 \%$ of the participants rated themselves to have PSQ. Evidence from previous studies among adolescents, such as in the USA [5], Taiwan [7], Turkey, [29] and Nigeria [3, 4] revealed higher rates, compared to the current report, which is higher than what was reported in India [30]. The disparity in rates may be related to the differences in research tools used to assess sleep quality, the definition of terms, as well as the age of the participants. For example, while the mean age of the participant in the current study is lower than those from the USA [5], Taiwan [7], Turkey, [29] and Nigeria [3, 4], it is slightly higher than the study from India which reported a lower prevalence [30]. It thus appears that increasing age is linked to higher sleep quality, having compared all these prevalence reports.

An earlier study has reported a different rate of sleep-related problems at different stages of adolescent development, with a lower rate at the early adolescence compared to late adolescence [4]. While the ranked mean age of those who reported poor quality of sleep in the present study was higher than those who did not, the difference was not statistically significant. This is similar to the report by Şimşek and Tekgül [29], who examined the effect of age on sleep quality even though a different screening tool was applied in their study. The effect of the biological changes which accompanies aging has been well acknowledged and said to account for the changes in sleep pattern in the adolescents. Notwithstanding, 
evidence pointing to the role of environmental elements, especially the modern-day technology, and those of the psychological disorders, are now evolving $[7,29]$. Some authors have linked the reduced need for sleep and an increasing stage of adolescence with increasing school and social demands [30,31]. Hence, the lack of association of age with sleep quality may simply suggest that environmental and psychosocial factors that are related to maturity are more likely to account for the increasing rate of poor sleep in older age groups rather than the effect of biological development. When we attempted to explore the possible social and environmental factors which may be responsible for PSQ in our sample using chisquare tests, four factors emerged. These include the current use of tobacco, internet use, depression, and anxiety disorders.

Tobacco use has been shown to reduce the quality of sleep [32,33], and high levels of withdrawal, and craving, have been associated with PSQ [33]. The present study revealed an association between tobacco use and PSQ, but when we included this variable in the logistic regression model, the association fizzled out. This suggests that some mediatory factors which explain the association between the two domains exist. Whilst it is necessary to further explore the relationship between tobacco use/abuse and sleep quality in a carefully selected sample, smokers should be well informed on the possible implication of smoking on sleep quality.

The rates of anxiety and depression amongst our participants are very high, as other reports from studies conducted among adolescents elsewhere [22,34]. Our study also revealed that the participants' sleep quality was significantly associated with these health conditions, as in other studies [10,11]. The composite relationship between sleep and psychological disorder, such as anxiety and depression in adolescents, has attracted much attention over time [10,35]. Although there has been mixed evidence regarding the bidirectional relationship between sleep and anxiety disorder [10], evidence supporting early sleep problems as a precursor to anxiety in adolescence is receiving a lot of attention [36-38]. Regulation of mood and emotion is contingent on adequate sleep. This is because the key neural regions and circuitry involved in emotional processing and regulation are highly active during sleep than during wakefulness [39]. In an experiment where adolescents were subjected to a mild sleep restriction protocol of 6.5 hours in bed per night for five consecutive nights, the participants were more irritable, oppositional, tense, and prone to emotional outbursts, compared with a healthy sleep duration plan [40]. Furthermore, a gradual sleep extension in adolescents experiencing a chronic reduced sleep duration was reported to significantly reduce depressive symptom severity in these individuals [41]. Early identification of sleep problems and effective interventions may be potential preventive measures for psychological disorders later in life. Conversely, poor sleep is one of the common symptoms of psychological disorders such as anxiety, depressive, and psychotic disorders [42]. Improved sleep quality is one of the earliest signs of remission of most psychological disorders, while poor quality of sleep is an early feature of relapse [42].

Our model also revealed a strong influence of internet use on sleep quality, as reported in some previous studies $[7,16]$. Internet access has contributed significantly to African growth in terms of economic and health promotion, but its excessive use has been associated with unwanted health outcomes, particularly psychological, especially in youth. The scientific explanations behind the link between internet use and 
poor sleep are poorly understood and beyond the scope of our study. One study has implicated the stimulating effect of the central nervous system, through participating in internet games and mind activating program at bedtime, on prolonged sleep latency [43]. Another possible theory is the suppressing effect of the blue light emission on the secretion melatonin from the pineal gland, which comes from internet-enabled devices, which may consequently result in the prolongation of sleep latency [44]. Alternatively, adolescents with sleeping difficulty may use the internet to engage themselves or cope with this problem rather than seeking professional help until they develop a medical or psychological disorder. However, the link between poor sleep and internet use should be further elucidated in African samples. In Africa, factors that encourage excessive and late-night internet use should be studied and addressed. Foremost amongst these factors is the availability of cheaper internet in the night, commonly called 'midnight internet package.' The typical sales advert 'trading sleep for data,' which encourages excessive midnight internet use should be discouraged. Perhaps, warning regarding the psychological effect of internet use at night should be attached to the advert as in the case of tobacco use.

Our study is limited in terms of generalisability to other regions in Nigeria. Also, convenience sampling applied in the study has limitations in prevalence studies. Furthermore, the analysis cannot determine the causal relationship between our outcome and the dependent variables due to its cross-sectional nature. A longitudinal study will be more applicable.

\section{Conclusions}

Our findings revealed PSQ in $12.2 \%$ of the adolescents that were sampled, and this falls towards the lower limit of the range reported elsewhere. Age, and use of stimulating drugs, were not found to predict the poor quality of sleep in our sample independently. Our study rather suggested the possible influence of psychological and environmental factors such as depression, anxiety, and internet use. We hypothesized that environmental and psychosocial factors that are age-related to maturity are more likely to account for the increasing rate of poor quality of sleep rather than the age effect of biological development. We, thus, recommend a more in-depth investigation of the interaction among these factors and sleep quality in a more carefully selected sample of adolescents. Importantly, we suggest further exploration of PSQ as a precursor of psychological disorders, as it may be one of the potential ways of preventing psychiatric disorders from developing later in life. Also, we prescribe the optimal management of psychological disorders, of which sleep problems are a typical fallout.

\section{Abbreviations}

PSQ poor sleep quality

HADS Hospital Anxiety Depression Scale

SQQ Sleep Quality Questionnaire 


\section{Declarations}

\section{Ethics approval and consent to participate}

Ethical approval was obtained from the Edo State Ministry of Education research and ethics committee (STT1465T/188), P.M.B. 1058, Benin City, Nigeria, and the authorities of the schools involved. Written informed consent was obtained from the participants and their parents/teachers if below the age of 18 years.

\section{Consent for publication}

Not applicable

\section{Availability of data and materials}

The datasets used and analyzed during the current study are available from the corresponding author on reasonable request

\section{Competing interests}

The authors declare none.

\section{Funding}

The authors received no financial support for the research, authorship, or publication of the article.

\section{Authors' contributions}

OAA and AOO $\left(1^{\text {st }}\right)$ conceptualized the study. AOO collected the data and carried out the analysis. OAA and $A O O\left(3^{\text {rd }}\right)$ wrote the initial draft. All the authors made significant intellectual input in the writing of the manuscript and agreed to the final draft.

\section{Acknowledgments}

The authors gratefully acknowledge the teachers and those who participated in this study.

\section{References}

1. Ohayon M, Wickwire EM, Hirshkowitz M, Albert SM, Avidan A, Daly FJ, Dauvilliers Y, Ferri R, Fung C, Gozal D: National Sleep Foundation's sleep quality recommendations: first report. Sleep health 2017, 3(1):6-19.

2. Hirshkowitz M, Whiton K, Albert SM, Alessi C, Bruni O, DonCarlos L, Hazen N, Herman J, Katz ES, Kheirandish-Gozal L: National Sleep Foundation's sleep time duration recommendations: methodology and results summary. Sleep health 2015, 1(1):40-43. 
3. Maduabuchi JC, Obu HA, Chukwu BF, Aronu AE, Manyike PC, Chinawa AT: Sleep pattern and practice among adolescents school children in Nigerian secondary schools. The Pan African medical journal 2014, 19.

4. Peter ID, Adamu H, Asani MO, Aliyu I, Sabo UA, Umar UI: Sleep pattern and sleep hygiene practices among Nigerian Schooling Adolescents. Indian journal of psychological medicine 2017, 39(4):407.

5. Lund HG, Reider BD, Whiting AB, Prichard JR: Sleep patterns and predictors of disturbed sleep in a large population of college students. Journal of adolescent health 2010, 46(2):124-132.

6. Kesintha A, Rampal L, Sherina M, Kalaiselvam T: Prevalence and predictors of poor sleep quality among secondary school students in Gombak District, Selangor. Med J Malays 2018, 73:31-40.

7. Wang P-Y, Chen K-L, Yang S-Y, Lin P-H: Relationship of sleep quality, smartphone dependence, and health-related behaviors in female junior college students. PloS one 2019, 14(4).

8. Patel SR, Hu FB: Short sleep duration and weight gain: a systematic review. Obesity 2008, 16(3):643653.

9. Seun-Fadipe CT, Mosaku KS: Sleep quality and psychological distress among undergraduate students of a Nigerian university. Sleep Health 2017, 3(3):190-194.

10. McMakin DL, Alfano CA: Sleep and anxiety in late childhood and early adolescence. Current Opinion in Psychiatry 2015, 28(6):483.

11. Guo L, Deng J, He Y, Deng X, Huang J, Huang G, Gao X, Lu C: Prevalence and correlates of sleep disturbance and depressive symptoms among Chinese adolescents: a cross-sectional survey study. BMJ open 2014, 4(7):e005517.

12. Gordon HW: Differential effects of addictive drugs on sleep and sleep stages. Journal of addiction research (OPAST Group) 2019, 3(2).

13. Clegg-Kraynok MM, McBean AL, Montgomery-Downs HE: Sleep quality and characteristics of college students who use prescription psychostimulants nonmedically. Sleep medicine 2011, 12(6):598-602.

14. Sobanski E, Schredl M, Kettler N, Alm B: Sleep in adults with attention deficit hyperactivity disorder (ADHD) before and during treatment with methylphenidate: a controlled polysomnographic study. Sleep 2008, 31(3):375-381.

15. Ogeil RP, Phillips JG: Commonly used stimulants: sleep problems, dependence and psychological distress. Drug and alcohol dependence 2015, 153:145-151.

16. Akçay D, Akçay BD: The influence of media on the sleep quality in adolescents. Turkish Journal of Pediatrics 2018, 60(3).

17. Ekinci Ö, Celik T, Savaş N, Toros F: Association between Internet use and sleep problems in adolescents. Nöro Psikiyatri Arşivi 2014, 51(2):122.

18. Orji M-L, Anyanwu OU, Ibekwe R, Onyire NB: Sleep hygiene of children in Abakaliki, Ebonyi state, Southeast Nigeria. Sahel Medical Journal 2017, 20(3):98.

19. Odey FA, Okokon IB, Ogbeche JO, Jombo G, Ekanem E: Prevalence of cigarette smoking among adolescents in Calabar city, south-eastern Nigeria. Journal of Medicine and Medical Sciences 2012, 
3(4):237-242.

20. Oshodi O, Aina O, Onajole A: Substance use among secondary school students in an urban setting in Nigeria: prevalence and associated factors. African journal of psychiatry 2010, 13(1).

21. Samuel NO: An evaluation of internet usage among senior secondary school students in public schools in Lagos State. 2010.

22. Gomes GC, dos Passos MHP, Silva HA, de Oliveira VMA, Novaes WA, Pitangui ACR, de Araújo RC: Sleep quality and its association with psychological symptoms in adolescent athletes. Revista Paulista de Pediatria 2017, 35(3):316.

23. Espie CA, Kyle SD, Hames P, Gardani M, Fleming L, Cape J: The Sleep Condition Indicator: a clinical screening tool to evaluate insomnia disorder. BMJ open 2014, 4(3):e004183.

24. Young K: Internet addiction test (IAT): Stoelting; 2016.

25. Khazaal Y, Billieux J, Thorens G, Khan R, Louati Y, Scarlatti E, Theintz F, Lederrey J, Van Der Linden M, Zullino D: French validation of the internet addiction test. CyberPsychology \& Behavior 2008, 11(6):703-706.

26. Zigmond AS, Snaith RP: The hospital anxiety and depression scale. Acta psychiatrica scandinavica 1983, 67(6):361-370.

27. Abiodun 0: A validity study of the Hospital Anxiety and Depression Scale in general hospital units and a community sample in Nigeria. The British Journal of Psychiatry 1994, 165(5):669-672.

28. Smart RG, Hughes P, Johnston LD, Anumonye A, Khant U, Mora M, Navaratnam V, Poshyachinda V, Varma V, Wadud K: A Methodology for student drug-use surveys/RG Smart...[et al.]. In: $A$ Methodology for student drug-use surveys/RG Smart[et al]. edn.; 1980.

29. Şimşek Y, Tekgül N: Sleep Quality in Adolescents in Relation to Age and Sleep-related Habitual and Environmental Factors. adolescence 2019, 2:5-7.

30. Dubey M, Nongkynrih B, Gupta SK, Kalaivani M, Goswami AK, Salve HR: Sleep quality assessment of adolescents residing in an urban resettlement colony, New Delhi, India. Indian journal of community medicine: official publication of Indian Association of Preventive \& Social Medicine 2019, 44(3):271.

31. Bruce ES, Lunt L, McDonagh JE: Sleep in adolescents and young adults. Clinical Medicine 2017, 17(5):424.

32. Liao Y, Xie L, Chen X, Kelly BC, Qi C, Pan C, Yang M, Hao W, Liu T, Tang J: Sleep quality in cigarette smokers and nonsmokers: findings from the general population in central China. BMC public health 2019, 19(1):808.

33. Purani H, Friedrichsen S, Allen AM: Sleep quality in cigarette smokers: Associations with smokingrelated outcomes and exercise. Addictive behaviors 2019, 90:71-76.

34. Kessler RC, Avenevoli S, Merikangas KR: Mood disorders in children and adolescents: an epidemiologic perspective. Biological psychiatry 2001, 49(12):1002-1014.

35. Chorney DB, Detweiler MF, Morris TL, Kuhn BR: The interplay of sleep disturbance, anxiety, and depression in children. Journal of pediatric psychology 2008, 33(4):339-348. 
36. Sadeh A, Tikotzky L, Kahn M: Sleep in infancy and childhood: implications for emotional and behavioral difficulties in adolescence and beyond. Current opinion in psychiatry 2014, 27(6):453-459.

37. Cowie J, Alfano CA, Patriquin MA, Reynolds KC, Talavera D, Clementi MA: Addressing sleep in children with anxiety disorders. Sleep Medicine Clinics 2014, 9(2):137-148.

38. Willis TA, Gregory AM: Anxiety disorders and sleep in children and adolescents. Sleep Medicine Clinics 2015, 10(2):125-131.

39. Goldstein AN, Walker MP: The role of sleep in emotional brain function. Annual review of clinical psychology 2014, 10:679-708.

40. Baum KT, Desai A, Field J, Miller LE, Rausch J, Beebe DW: Sleep restriction worsens mood and emotion regulation in adolescents. Journal of Child Psychology and Psychiatry 2014, 55(2):180-190.

41. Dewald-Kaufmann J, Oort F, Meijer A: The effects of sleep extension and sleep hygiene advice on sleep and depressive symptoms in adolescents: a randomized controlled trial. Journal of Child Psychology and Psychiatry 2014, 55(3):273-283.

42. Krystal AD: Psychiatric disorders and sleep. Neurologic clinics 2012, 30(4):1389-1413.

43. Higuchi S, Motohashi Y, Liu Y, Maeda A: Effects of playing a computer game using a bright display on presleep physiological variables, sleep latency, slow wave sleep and REM sleep. Journal of sleep research 2005, 14(3):267-273.

44. Moderie C, Van der Maren S, Dumont M: Circadian phase, dynamics of subjective sleepiness and sensitivity to blue light in young adults complaining of a delayed sleep schedule. Sleep medicine 2017, 34:148-155.

\section{Tables}

Table 1: Participants' characteristics 


\begin{tabular}{|c|c|c|}
\hline Variables & & Frequency (\%) \\
\hline \multirow[t]{2}{*}{ *Gender } & Male & $174(46.2)$ \\
\hline & Female & $203(53.8)$ \\
\hline \multirow[t]{2}{*}{ *School } & Public & $189(50.8)$ \\
\hline & Private & $183(49.2)$ \\
\hline \multirow[t]{2}{*}{ *Ethnicity } & Bini & $159(43.9)$ \\
\hline & Non-Bini & $203(56.1)$ \\
\hline \multirow[t]{2}{*}{ *Family } & Monogamy & $294(80.5)$ \\
\hline & Polygamy & $71(19.5)$ \\
\hline \multirow[t]{2}{*}{ *Religion } & Christianity & $359(95.7)$ \\
\hline & Others & $16(4.3)$ \\
\hline \multirow[t]{3}{*}{ *Parental figure } & Single parent & $77(20.4)$ \\
\hline & Both parent & $242(64.2)$ \\
\hline & Guardian & $58(15.4)$ \\
\hline \multirow[t]{2}{*}{ *Academic performance } & Above average & $285(77.2)$ \\
\hline & Average \& below & $84(22.8)$ \\
\hline \multirow[t]{2}{*}{ Current caffeine use } & No & $229(60.6)$ \\
\hline & Yes & 149 (39.4) \\
\hline \multirow[t]{2}{*}{ Current tobacco use } & No & $355(93.9)$ \\
\hline & Yes & $23(6.1)$ \\
\hline \multirow[t]{2}{*}{ Depression } & Non-cases & $266(70.4)$ \\
\hline & Cases & $112(29.6)$ \\
\hline \multirow[t]{2}{*}{ Anxiety } & Non-cases & $195(51.6)$ \\
\hline & Cases & $183(48.4)$ \\
\hline \multirow[t]{2}{*}{ Sleep quality } & Normal & $332(87.8)$ \\
\hline & Poor & $46(12.2)$ \\
\hline \multirow[t]{2}{*}{ Internet use } & Normal & $290(76.7)$ \\
\hline & Problematic & $88(23.3)$ \\
\hline
\end{tabular}

*Missing data 
Table 2: Association between sleep quality and participants' characteristics

\begin{tabular}{|c|c|c|c|c|}
\hline \multirow[t]{2}{*}{ Variables } & & \multicolumn{2}{|c|}{ Sleep quality } & \multirow[t]{2}{*}{ p-value } \\
\hline & & Normal (\%) & Poor (\%) & \\
\hline \multirow[t]{2}{*}{ Gender } & Male & $155(89.1)$ & 19 (10.9) & 0.48 \\
\hline & Female & $176(86.7)$ & $27(13.3)$ & \\
\hline \multirow[t]{2}{*}{ School } & Public & $164(86.8)$ & $25(13.2)$ & 0.49 \\
\hline & Private & $163(89.1)$ & $20(10.9)$ & \\
\hline \multirow[t]{2}{*}{ Family } & Monogamy & $262(89.1)$ & $32(10.9)$ & 0.28 \\
\hline & Polygamy & $60(84.5)$ & $11(15.5)$ & \\
\hline \multirow[t]{2}{*}{ Academic performance } & Above average & $255(89.5)$ & $30(10.5)$ & 0.07 \\
\hline & Average \& below & $69(82.1)$ & 15 (17.9) & \\
\hline \multirow[t]{2}{*}{ Current caffeine use } & No & $203(88.6)$ & $26(11.4)$ & 0.55 \\
\hline & Yes & $129(86.6)$ & $20(13.4)$ & \\
\hline \multirow[t]{2}{*}{ Current tobacco use } & No & $316(89.0)$ & $39(11.0)$ & 0.01 \\
\hline & Yes & $16(69.6)$ & $7(30.4)$ & \\
\hline
\end{tabular}

Table 3: Relationships of age, anxiety, depression and internet use, with sleep quality 


\begin{tabular}{llllll} 
Variables & Sleep quality & Mean rank & MWU & Z & p-value \\
\hline Age & & & 6388.50 & -0.31 & 0.75 \\
& Normal & 171.37 & & & \\
& Poor & 176.31 & & & \\
\hline Depression & & & 5305.00 & -3.37 & 0.00 \\
& Normal & 182.48 & & & \\
& Poor & 240.17 & & & \\
\hline Anxiety & & & 4417.50 & -4.65 & 0.00 \\
& Normal & 179.81 & & & \\
& Poor & 259.47 & & & \\
\hline Internet use & & & 5918.50 & -2.48 & 0.01 \\
& Normal & 184.33 & & & \\
& Poor & 226.84 & & &
\end{tabular}

Note: Normal $(n=332)$, Poor use $(n=46)$, MWU - Man-Whitney U

Table 4: Logistic regression of tobacco use, internet use, depression and anxiety on sleep quality

\begin{tabular}{llllll} 
Independent Variable & B & S.E. & df & Sig. & AOR $(95 \%$ Cl) \\
\hline Current tobacco use & -0.81 & 0.51 & 1 & 0.11 & $0.45(0.16-1.21)$ \\
\hline Internet use & 0.02 & 0.01 & 1 & $\mathbf{0 . 0 4}$ & $1.02(1.00-1.03)$ \\
\hline Depression & 0.12 & 0.06 & 1 & $\mathbf{0 . 0 4}$ & $1.12(1.00-1.25)$ \\
\hline Anxiety & 0.19 & 0.05 & 1 & $\mathbf{0 . 0 0}$ & $1.20(1.10-1.32)$
\end{tabular}

